Jurnal Ilmiah Matematika dan Pendidikan Matematika (JMP)

Vol. 11 No. 2, Desember 2019, hal. 51-58

ISSN (Cetak) : 2085-1456; ISSN (Online) : 2550-0422

\title{
PROFIL REPRESENTASI VISUAL MAHASISWA PADA MATA KULIAH GEOMETRI
}

\author{
Najmah Istikaanah \\ Jurusan Matematika Universitas Jendral Soedirman \\ najmah.mtk@unsoed.ac.id \\ Muhammad Prayito \\ Pendidikan Matematika Universitas PGRI Semarang
}

\begin{abstract}
The specific purpose of this study is to determine the profile of visual representation of students in geometry courses. This research is a qualitative research. The data collection method is done through documentation, observation, learning achievement tests and questionnaires. The results showed that the ability of visual representation of 1st semester students at mathematics education was still low. This is reviewed in the student's ability to answer learning achievement test at geometry courses.
\end{abstract}

Keywords: learning achievement, visual representation, geometry.

ABSTRAK. Tujuan khusus penelitian ini adalah mengetahui profile representasi visual mahasiswa pada mata kuliah Geometri. Penelitian ini merupakan penelitian kualitatif. Metode pengambilan data dilakukan melalui dokumentasi, observasi, tes hasil belajar dan angket. Hasil penelitian menunjukkan bahwa kemampuan representasi visual mahasiswa semester 1 program studi pendidikan matematika masih rendah. Hal tersebut ditinjau pada kemampuan mahasiswa untuk menjawab soal tes hasil belajar mata kuliah Geometri.

Kata Kunci: Hasil Belajar, Representasi Visual, Geometri

\section{PENDAHULUAN}

Menurut Soedjadi (1991) bahwa kesulitan-kesulitan sering yang dialami peserta didik dalam pembelajaran Geometri antara lain representasi visual unit Geometri tampak dan yang tidak tampak, misalnya peserta didik sukar menentukan apakah suatu sudut siku-siku atau tidak; sukar mengenali dan memahami bangun-bangun Geometri terutama bangun ruang serta unsurunsurnya. Lebih jauh David Tall (2004) menyebutkan Geometri dapat diwujudkan secara konseptual seperti Geometri Euclide sedangkan untuk Geometri nonEuclide bisa dibayangkan visuospasialnya pada permukaan selain ruang Euclide datar. Masalah visualisasi juga menjadi hambatan dalam meningkatkan hasil 
belajar Geometri di Universitas PGRI Semarang. Mahasiswa kurang mampu dalam melakukan representasi visual atas objek Geometri yang sedang mereka pelajari.

Peraturan Menteri Pendidikan dan Kebudayaan Republik Indonesia Nomor 49 Tahun 2014 tentang Standar Nasional Pendidikan Tinggi dinyatakan bahwa kurikulum adalah seperangkat rencana dan pengaturan mengenai capaian pembelajaran lulusan, bahan kajian, proses, dan penilaian yang digunakan sebagai pedoman penyelenggaraan program studi.Peraturan Menteri Pendidikan dan Kebudayaan Republik Indonesia Nomor 73 Tahun 2013 tentang Penerapan Kerangka Kualifikasi Nasional Indonesia Bidang Pendidikan Tinggi pada pasal 10 ayat 4, yakni : setiap program studi wajib menyusun deskripsi capaian pembelajaran minimal mengacu pada KKNI bidang pendidikan tinggi sesuai dengan jenjang. Deskripsi capaian pembelajaran dalam KKNI, mengandung empat unsur, yaitu unsur sikap dan tata nilai, unsur kemampuan kerja, unsur penguasaan keilmuan, dan unsur kewenangan dan tanggung jawab.

Media pembelajaran harus dapat berfungsi sebagai alat komunikasi dalam penyampaian pembelajaran. Agar inovasi media pembelajaran berhasil optimum sesuai dengan tujuan yang diinginkan maka beberapa hal perlu dipertimbangkan dalam inovasi seperti rasional teoritis, landasan pemikiran pembelajaran dan lingkungan belajar. Pemilihan media pembelajaran yang sesuai dapat dipergunakan untuk melatih kemampuan representasi visual mahasiswa. Salah satu software yang mendukung kemampuan belajar Geometri adalah geogebra (Farida, Bagus dan Prayito. 2016). Geogebra mempunya tampilan 2D dan 3D yang diharapkan akan membantu meningkatkan hasil belajar mahasiswa pada mata kuliah Geometri.

Berdasarkan uraian diatas maka rumusan masalah pada penelitian ini adalah bagaimana profil representasi visual mahasiswa pada mata kuliah Geometri dengan harapan nantinya dapat di munculkan inovasi media pembelajara yang dapat meningkatkan hasil belajar mahasiswa pada mata kuliah Geometri. 


\section{METODE PENELITIAN}

Penelitian ini termasuk dalam penelitian kualitatif. Penelitian kualitatif (qualitative Research) adalah suatu penelitian yang ditujukan untuk mendeskripsikan dan menganalisis fenomena, peristiwa, aktifitas social, sikap, kepercayaan, persepsi, pemikiran orang secara individual maupun kelompok. Beberapa deskripsi digunakan untuk menemukan prinsip-prinsip dan menjelaskan yang mengarah pada penyimpulan. Penelitian kualitatif bersifat induktif, peneliti membiarkan permasalahan-permasalahan muncul dari data atau dibiarkan terbuka untuk interpetasi. Data dihimpun dengan pengamatan yang seksama, mencakup deskripsi dalam konteks yang mendetail disertai catatan-catatan hasil wawancara yang mendalam, serta hasil analisis dokumen dan catatan-catatan.

Penelitian kualitatif adalah penelitian yang bermaksud untuk memahami fenomena tentang apa yang dialami oleh subjek penelitian misalnya prilaku, persepsi, motivasi, tindakan, dll. (Moleong, 2005). Penelitian kualitatif mempunyai dua tujuan utama, yang pertama yaitu, menggambarkan dan mengungkap (to describe and explore) dan kedua menggambarkan dan menjelaskan (to describe and explain).

Penelitian ini dilaksanakan di Program Studi Pendidikan Matematika Universitas PGRI Semarang, khususnya pada mahasiswa kelas 1B. Mata kuliah yang menjadi sasaran penelitian ini adalah mata kuliah Geometri.

Analisis pemeriksaan keabsahan data guna kesempurnaan, validitas data, keakuratan informasi, dan originalitas sumber-sumber dalam penelitian ini amenggunakan triangulasi. Triangulasi menurut Moleong (2005) adalah tekhnik pemeriksaan keabsahan data yang memanfaatkan sesuatu yang lain diluar data itu, untuk keperluan pengecekan atau pembanding terhadap data tersebut.

\section{HASIL DAN PEMBAHASAN}

Pada awalnya dilakukan penelitian yang bersifat deskriptif terlebih dahulu dengan tujuan untuk mendapatkan gambaran dan informasi tentang pembelajaran Geometri. Penelitian ini ditekankan untuk memperoleh gambaran tentang penerapan media pembelajaran, pelaksanaan proses pembelajaran, aktivitas 
mahasiswa dan dosen, keterlaksanaan rencana pembelajaran, dan hasil belajar mahasiswa.

Mata kuliah Geometri merupakan mata kuliah wajib untuk mahasiswa pendidikan matematika semester 1. Beban SKS mata kuliah Geometri adalah 3 SKS. Perkuliahan kelas 1B dilaksanakan setiap hari senin jam 13.00-15.30 WIB. Selama semester perkuliahan Geometri dilaksanakan 14 kali pertemuan. Jumlah mahasiswa yang mengikuti kuliah Geometri adalah 30 mahasiswa. Materi mata kuliah Geometri terdiri dari dua materi utama yaitu Geometri datar dan Geometri ruang. Materi Geometri datar dilaksanakan sebelum UTS (Ujian Tengah Semester) dan materi Geometri ruang dilaksanakan setelah UTS. Rencana pembelajaran mata kuliah Geometri dilakukan dengan pendekatan kooperatif. Media yang digunakan dalam proses pembelajaran adalah software geogebra. Sedangkan alat yang digunakan adalah spidol, whiteboard dan LCD proyektor.

Proses pembelajaran pada mata kuliah Geometri dapat dilaksanakan dengan baik. Dosen dan mahasiswa dapat berinteraksi dengan baik. Mahasiswa cukup aktif dalam proses pembelajaran. Mahasiswa selalu berangkat kuliah selama satu semester, hanya ada 2 mahasiswa yang pernah izin tidak berangkat dikarenakan sakit. Sebanyak 19 mahasiswa sudah pernah bertanya pada proses pembelajaran mata kuliah Geometri.

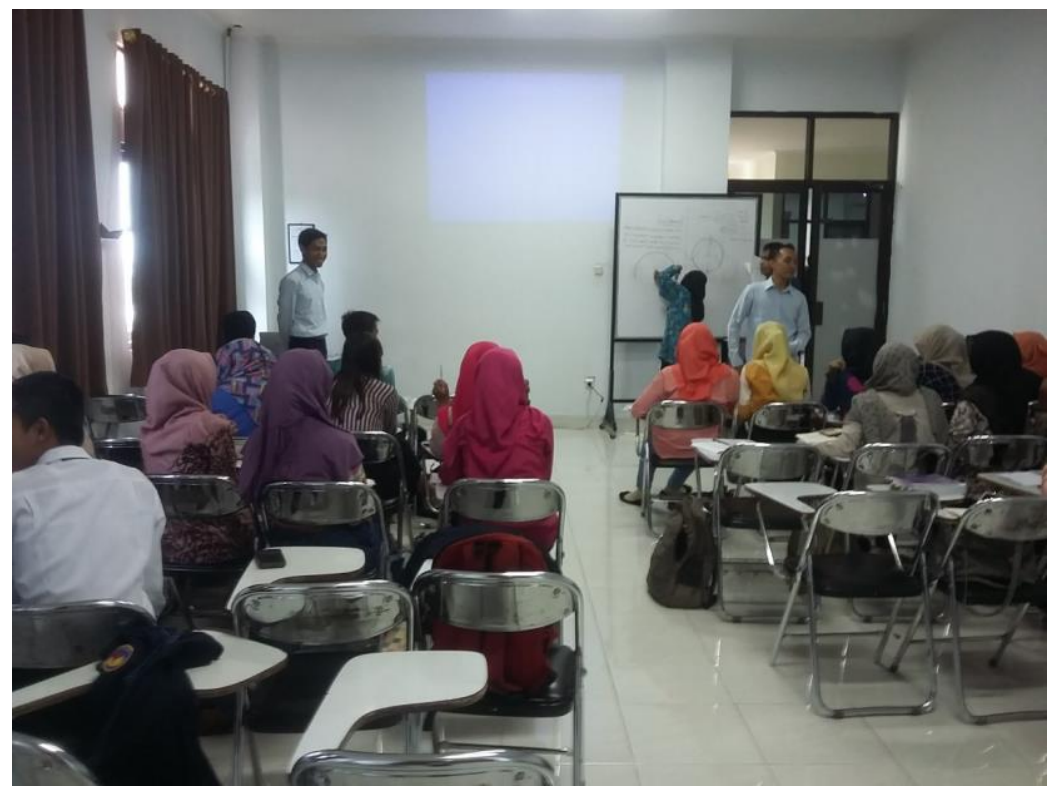

Gambar 3.1 Proses kegiatan pembelajaran mata kuliah Geometri 


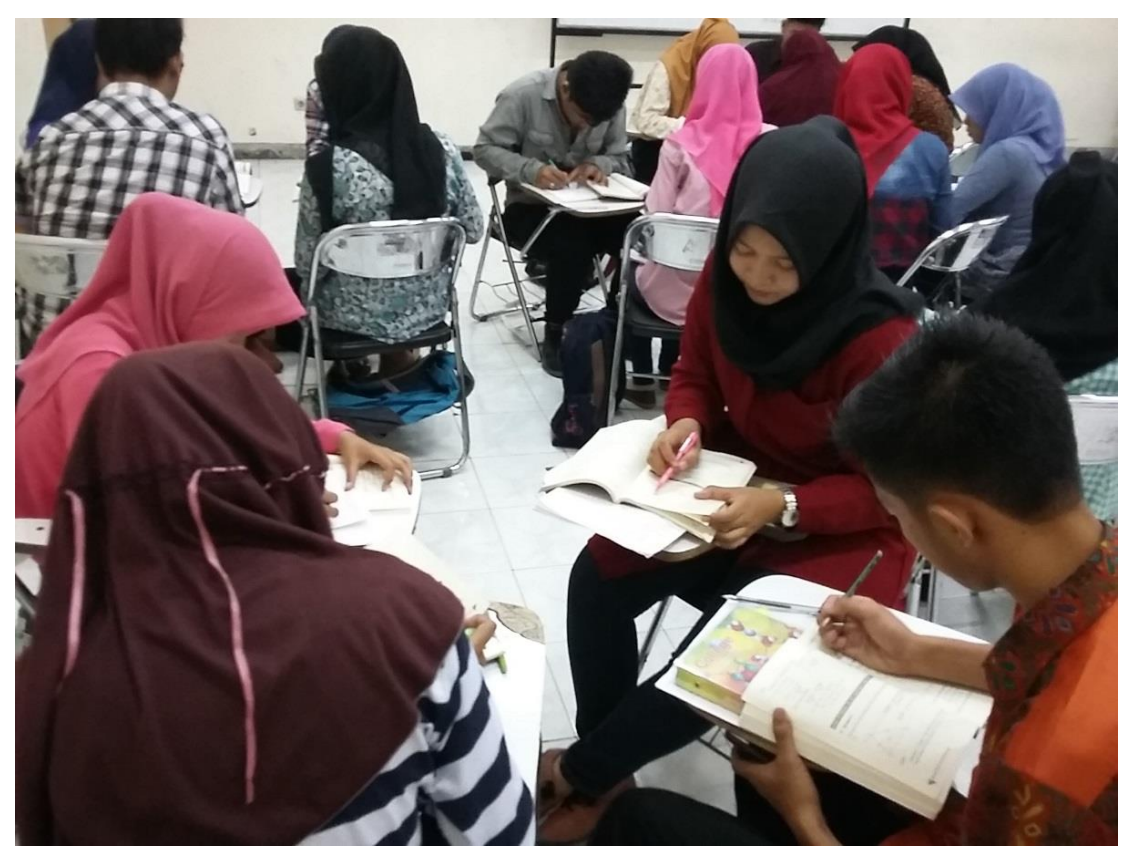

Gambar 3.2 Diskusi kelompok mata kuliah Geometri

Hasil belajar kognitif siswa dikumpulkan dengan memberikan 5 soal tes uraian. Setiap soal mempunyai penyelesian dengan cara visual dan analisis. Sehingga untuk menyelesaikan soal 1 sampai dengan nomor 5 mahasiswa harus menggambar terlebih dahulu objek Geometri soal. Tahap tahap gambar ini diselidiki kemampuan mahasiswa dalam membuat visualisasi objek Geometri yang tepat sesuai teori level berpikir Van Hiele.

Semua mahasiswa yang mengerjakan soal tes mengawali proses pencarian jawaban dengan melakukan visualisasi. Tetapi hasil visualisasi yang dibuat oleh mahasiswa banyak yang mengalami kesalahan. Pada soal nomor 1, mahasiswa yang benar dalam membuat visualisasi adalah 16 mahasiswa. Pada soal nomor 2, mahasiswa yang benar dalam membuat visualisasi adalah 12 mahasiswa. pada pada soal nomor 3, mahasiswa yang benar dalam membuat visualisasi adalah 24 mahasiswa. Pada soal nomor 4, mahasiswa yang benar dalam melakukan visualisasi adalah 19 mahasiswa. Pada soal nomor 5, mahasiswa yang benar dalam melakukan visualisasi adalah 15 mahasiswa.

Pada soal nomor 2 mahasiswa cenderung salah dalam meletakan bagian frontal objek Geometri. sebagian besar mahasiswa hanya mengarsir daerah yang 
seharusnya frontal tapi digambar tetap dalam posisi miring ataupun membagi diagonal. Kesalahan lain juga ditemukan pada soal no 4 yaitu mahasiswa membuat daerah frontal sembarang, artinya titik sudut yang seharusnya mempunyai nama urut abjad $\mathrm{ABCD}$ dibuat tidak beraturan agar mendapatkan bagian frontal yang sesuai soal. Berikut gambar jawaban mahasiswa pada nomor 4.

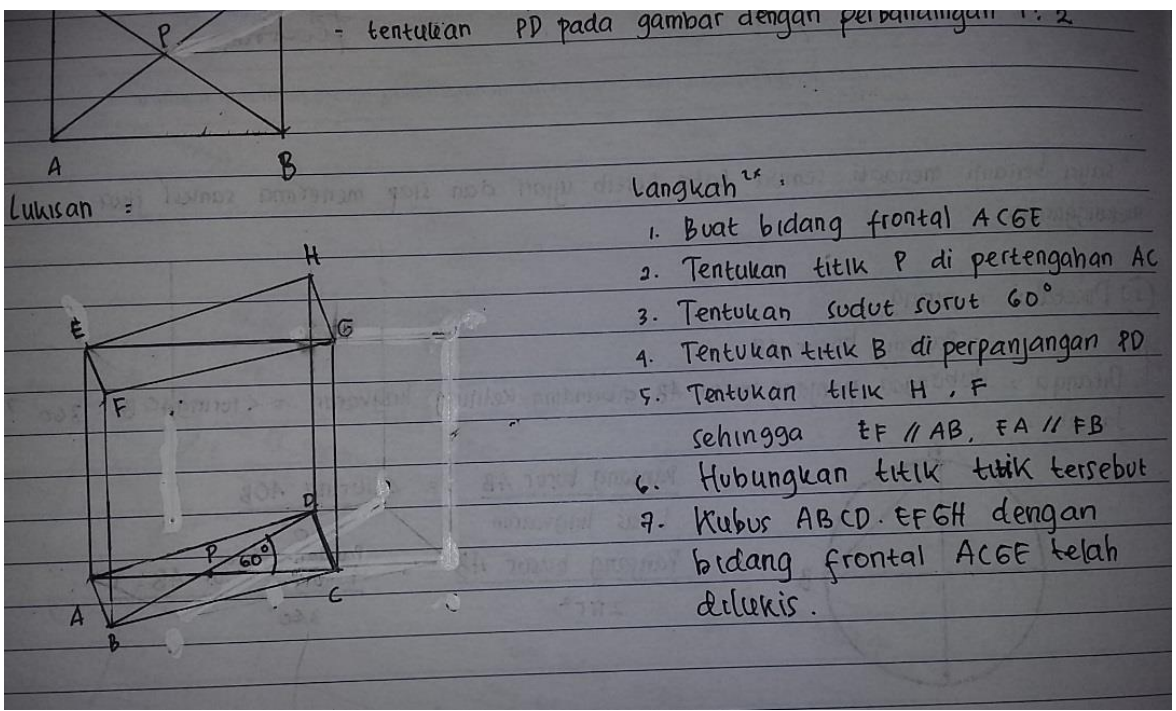

Gambar 3.3 Jawaban mahasiswa yang sudah tepat meletakan bagian frontal sesuai soal

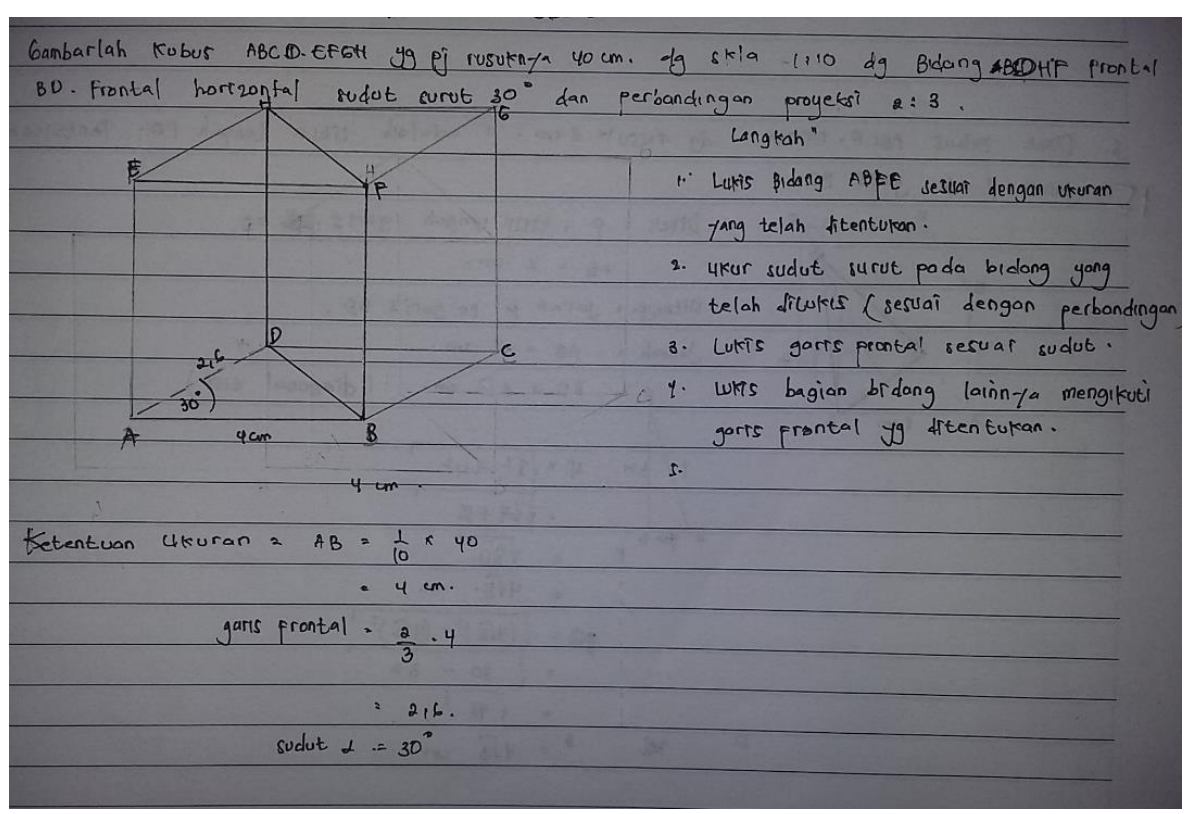

Gambar 3.4 Jawaban mahasiswa yang masih salah dalam meletakan bagian frontal sesuai soal. 
Tahap analisis soal dari soal 1-soal nomor 5 merupakan lanjutan dari tahap visualisasi. Sehingga mahasiswa yang sudah salah di tahap visualisasi maka akan salah ditahap analisis. Hal ini disebabkan karena karena ukuran objek dan pengetahuan awal dari gambar objek akan dibawa dan diolah untuk menjadi analisis mahasiswa. Hasil ini sesuai dengan penelitian Lavy (2006) bahwa Visualisasi memiliki peran penting dalam pengembangan pemikiran, pemahaman matematis dan dalam transisi dari berpikir konkrit ke abstrak berkaitan dengan pemecahan masalah matematis. Pada tahap analisis yang menjadi kajian adalah soal nomor 3, 4 dan 5 karena pada soal tersebut berisi lebih banyak tentang analisis perhitungan.

\section{KESIMPULAN DAN SARAN}

Kesimpulan yang dapat diambil dari hasil dan pembahasan adalah Kemampuan representasi visual mahasiswa semester 1 program studi pendidikan matematika masih rendah. Hal tersebut ditinjau pada kemampuan mahasiswa untuk menjawab soal tes

\section{UCAPAN TERIMAKASIH}

Ucapan terimakasih diberikan kepada banyak pihak yang telah banyak memberikan bantuan dan dukungannya sehingga artikel penelitian ini dapat terselesaikan.

\section{DAFTAR PUSTAKA}

Tall, D., Thinking through three worlds of mathematics, In Proceedings of the 28th Conference of the International Group for the Psychology of Mathematics Education, 4 (2004), 281-288.

Depdiknas, Salinan Lampiran Permendikbud No. 73 th 2013: Tentang Kerangka Kurikulum Nasional Indonesia, Depdiknas, Jakarta, 2013.

Depdiknas, Salinan Lampiran Permendikbud No. 49 th 2014: Tentang Kerangka Kurikulum Nasional Indonesia, Depdiknas, Jakarta, 2014. 
Dimakos, G., Nikoloudakis, E., Ferentinos, S., dan Choustoulakis, E., Developing a proof-writing tool for novice Lyceum Geometry students, The Teaching Of Mathematics, 10(2) (2007).

Fitriani, Pengaruh Self Esteem dan Self Regulation terhadap Hasil Belajar Matematika Siswa, Jurnal BIOTEK, 4(2) (2016).

John, W. S. A., Perkembangan Remaja, Edisi Keenam, Penerbit Erlangga, Jakarta, 2003.

Lavy, I., Dynamic Visualization and The Case of Stars in Cages, Proceedings of 30th Conference of the International Group for the, 2006.

Marzano, R. J., Classroom Management that Works, Pearson Education ASCD, New Jersey, 2009.

Moleong, L. J., Metodologi Penelitian Kualitatif, Remaja Rosda Karya, Bandung, 2005.

National Education Association, Audiovisual Instruction Department, New Media and College Teaching,NEA, Washington, D.C., 1969.

Prayito, Farida dan Bagus, Media Pembelajaran Geometri Menggunakan Pendekatan Realistik Pendidikan Matematika Berbasis Geogebra, INSPIRATIF, 1(2) (2015).

Robert, A. B. dan Byrne, D., Psikologi Sosial. Penerbit Erlangga, Jakarta, 2014.

Sarwono, S. W. dan Eko, A. M., Psikologi Sosial, Salemba Humanika, Jakarta, 2011.

Soedjadi, Wajah Pendidikan Matematika Sekolah Dasar Kita (Beberapa Pengamatan Lapangan Sebagai Upaya Perbaikan di Masa Depan). Makalah Penataran Penyiapan Calon Penatar Dosen PGSD - DII Guru Kelas, Jakarta, 1991.

Sudjana dan Rivai, Media Pendidikan, Balai Pustaka, Jakarta, 2002.

Zimmermann, W. dan Cunningham, S., Editor's Introduction : What is Mathematical Visualization ?, Zimmermann W. and Cunningham S. (eds.) Vizualization in Teaching and Learning Mathematics, 1-8, Mathematical Association of America, Washington D.C., 1991 